\title{
Fabrication of Nanoscale Cage Cubes by Drilling Orthogonal, Intersected Holes through All Six Side Faces of Ag Nanocubes
}

Jaewan Ahn and Dong Qin*

School of Materials Science and Engineering, Georgia Institute of Technology, Atlanta, Georgia 30332, United States

*Corresponding author: dong.qin@mse.gatech.edu

Keywords: nanoscale cage cubes; core-frame nanocubes; galvanic replacement; site-selected etching; site-selected deposition 


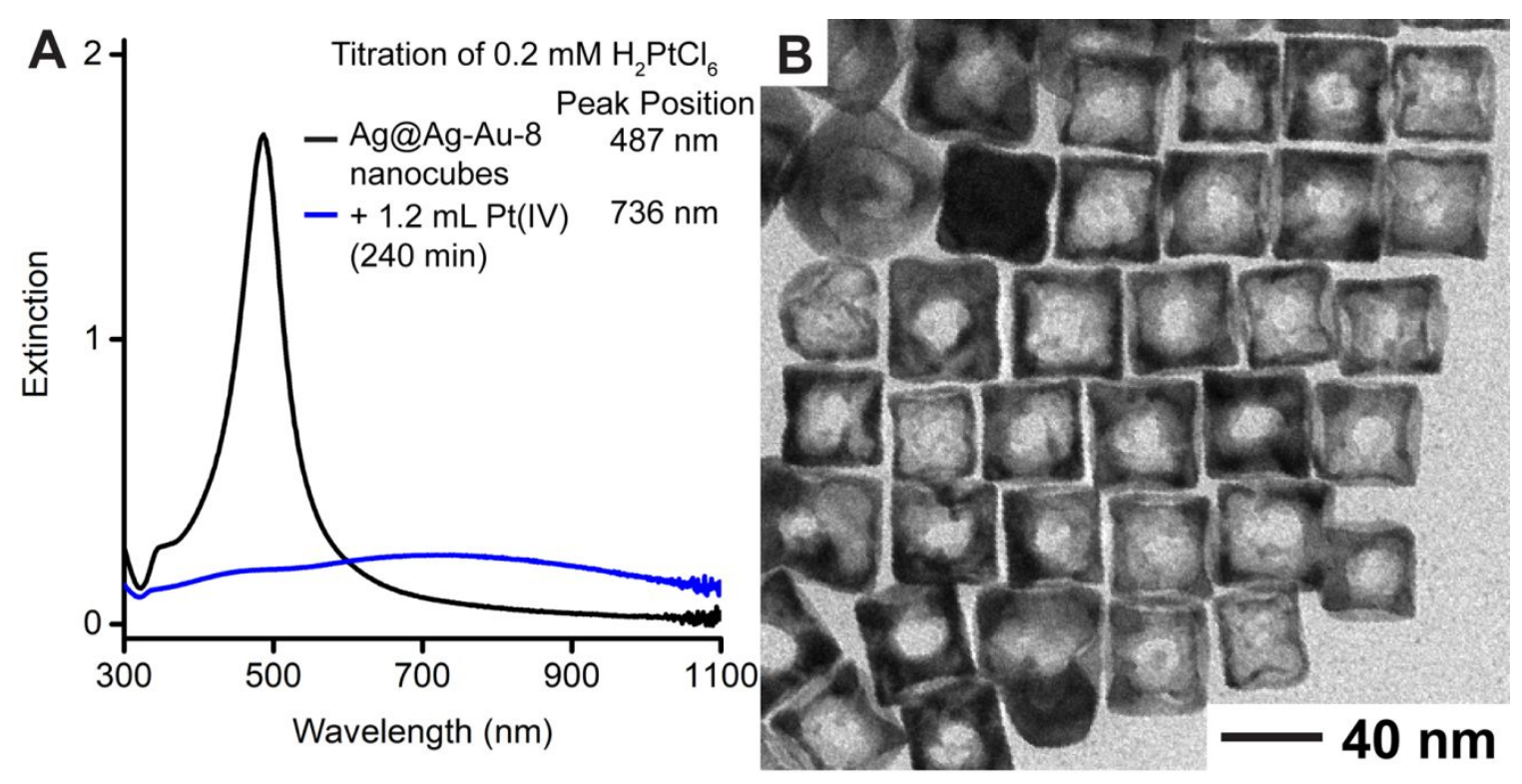

Figure S1. (A) UV-vis spectra of the Ag@Ag-Au-8 nanocubes before and after reacting with 1.2 $\mathrm{mL} \mathrm{H}_{2} \mathrm{PtCl}_{6}(0.2 \mathrm{mM})$ at the reaction time point of $240 \mathrm{~min}$. (B) TEM image of the product. 


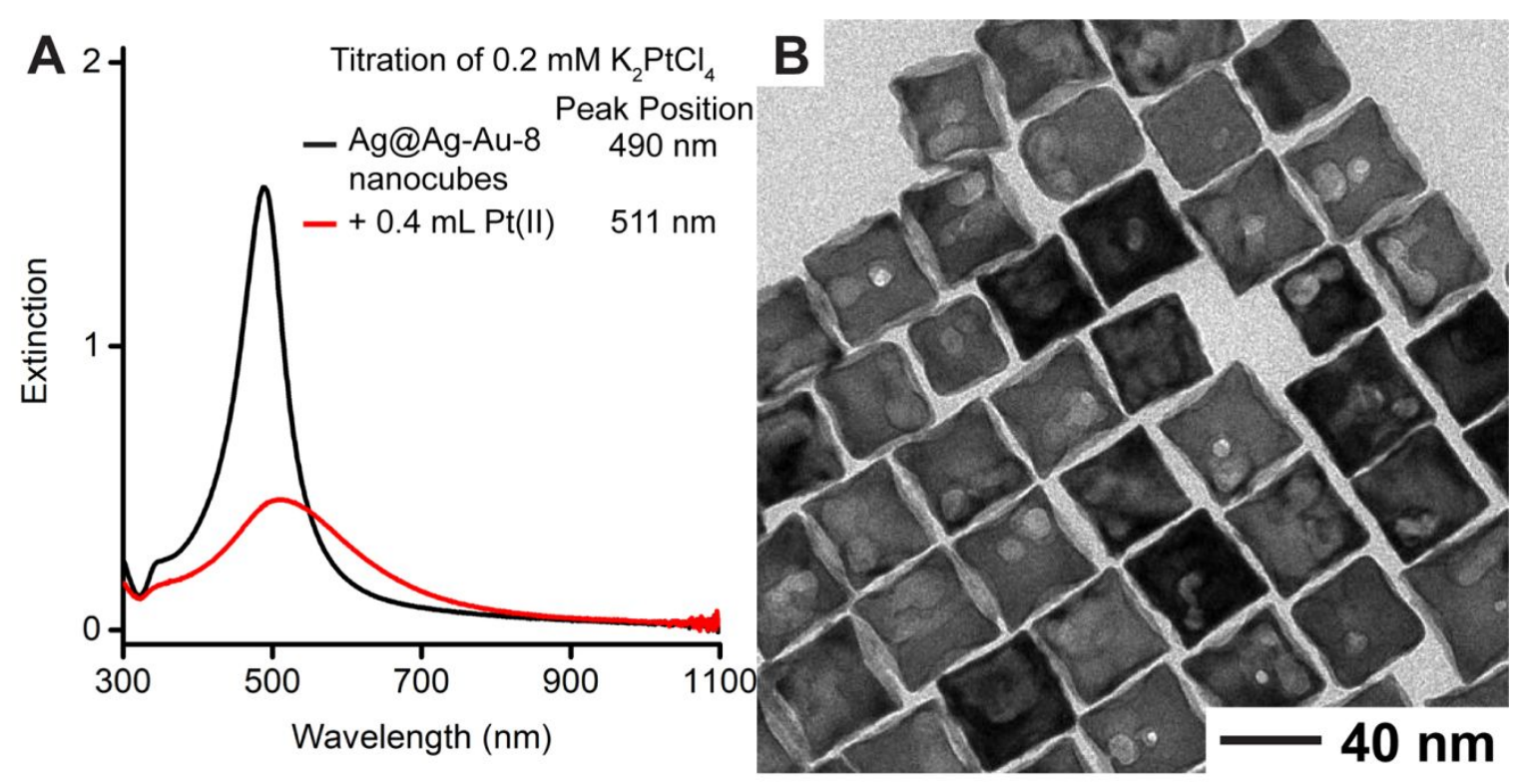

Figure S2. (A) UV-vis spectra of the Ag@Ag-Au-8 nanocubes before and after reacting with 0.4 $\mathrm{mL} \mathrm{K}_{2} \mathrm{PtCl}_{4}(0.2 \mathrm{mM})$. (B) TEM image of the product. 


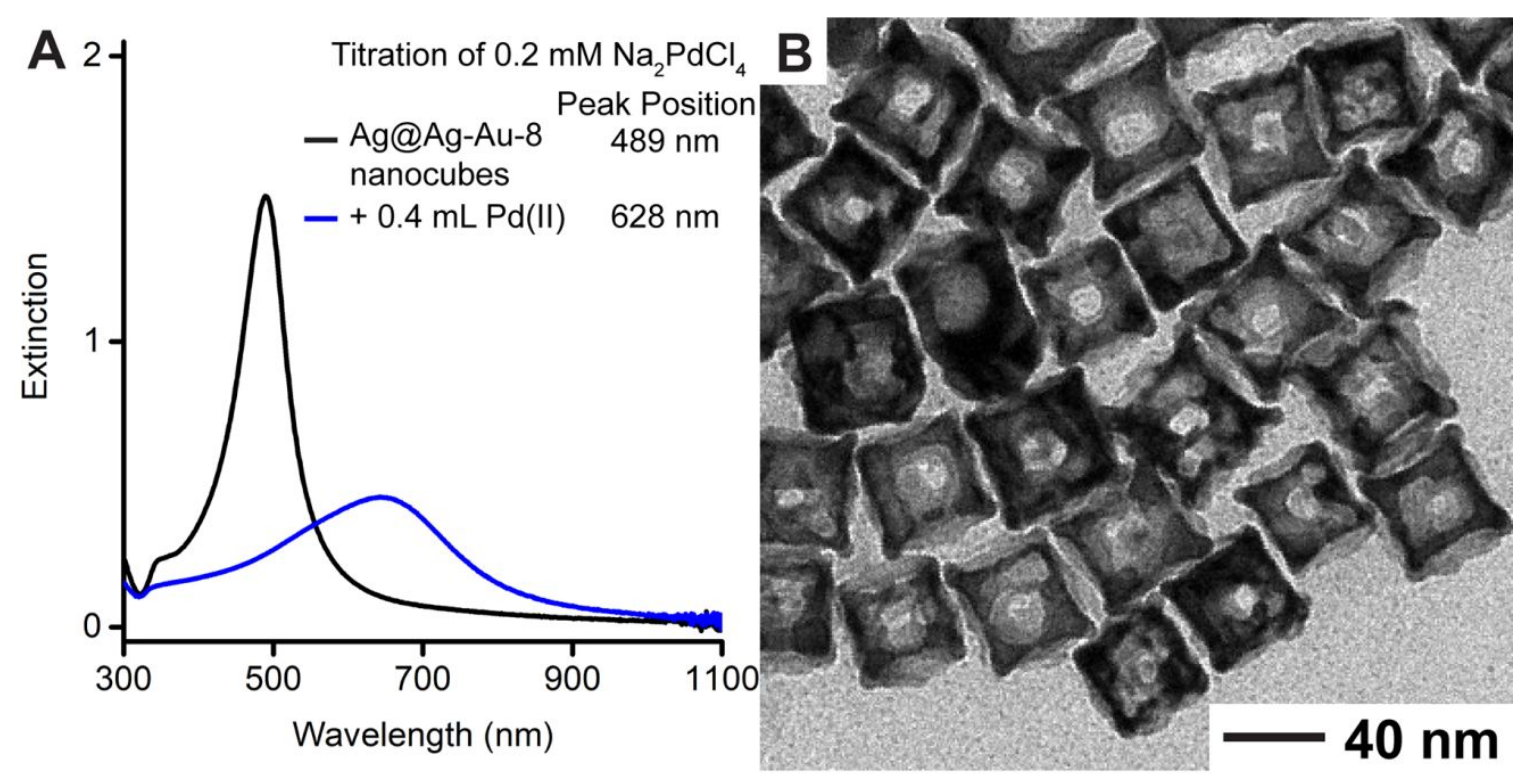

Figure S3. (A) UV-vis spectra of the Ag@Ag-Au-8 nanocubes before and after reacting with 0.4 $\mathrm{mL} \mathrm{Na}_{2} \mathrm{PdCl}_{4}(0.2 \mathrm{mM})$. (B) TEM image of the product. 


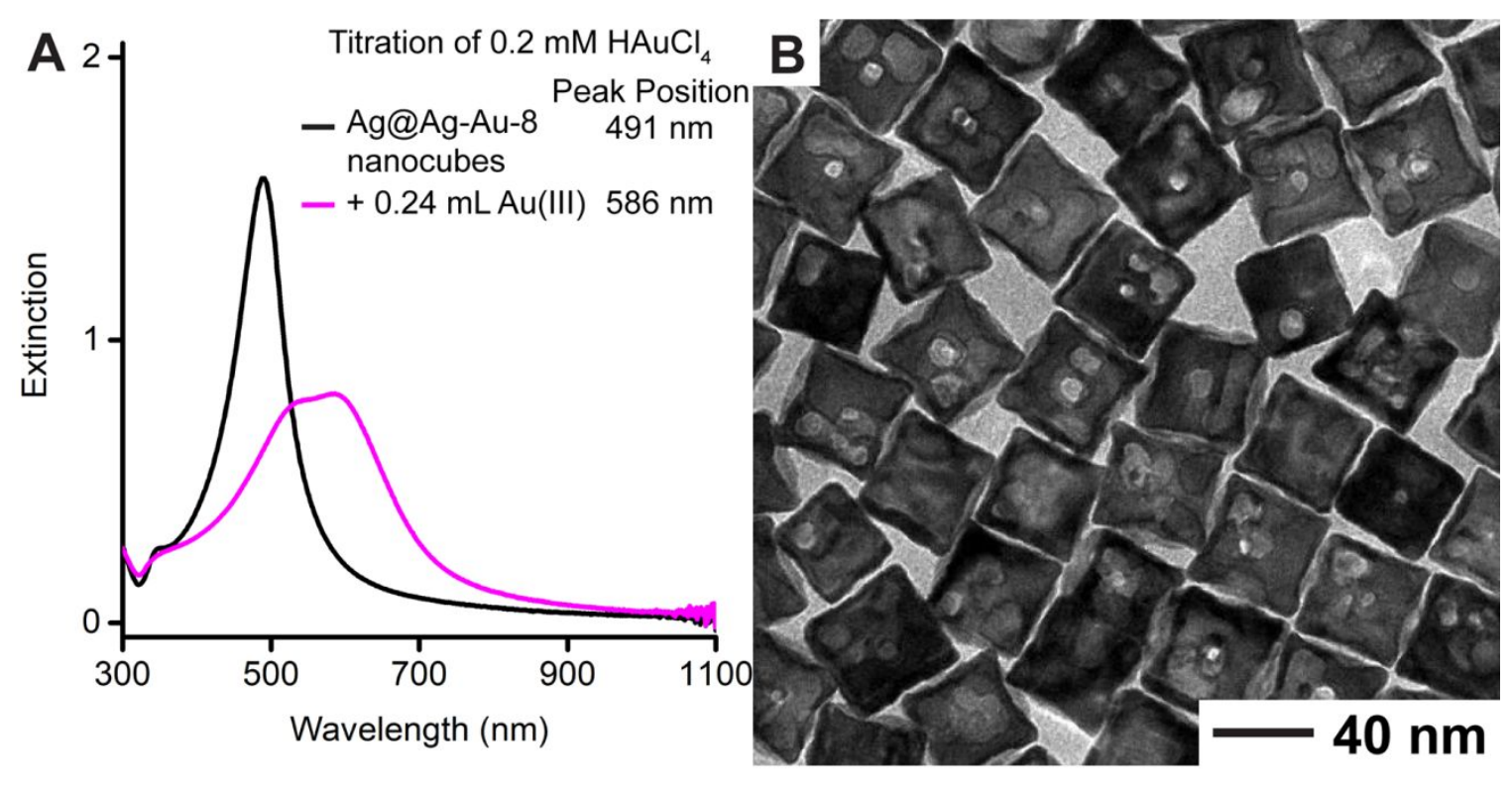

Figure S4. (A) UV-vis spectra of the Ag@Au-Ag-8 nanocubes before and after reacting with 0.24 $\mathrm{mL} \mathrm{HAuCl}_{4}(0.2 \mathrm{mM})$. (B) TEM image of the product. 